\title{
In-Vitro Evaluation of Antifungal Properties of Dadrughn Lepa and its New Dosage Forms against Dermatophytes
}

\author{
Arun Sharma ${ }^{1}$, Dr. Shuchi Mitra ${ }^{2}$, Dr. Yadevendra Yadav ${ }^{3 *}$, Dr. Khem Chand Sharma ${ }^{4}$ \\ ${ }^{1}$ P G Scholar, ${ }^{2}$ Associate Professor, ${ }^{3}$ Assistant Professor, ${ }^{4}$ Professor and Head, P.G. Department of Rasa Shastra \& Bhaishajya Kalpana, Uttarakhand
} Ayurveda University, Rishikul Campus, Haridwar, Uttarakhand, India

DOI: $10.36348 /$ sijtcm.2020.v03i04.001

| Received: 19.03.2020 | Accepted: 27.03.2020 | Published: 30.04.2020

*Corresponding author: Yadevendra Yadav

\section{Abstract}

In Ayurveda word, 'Kushtha' means a pathological condition which despises the skin. Majority of the dermatological disorders have been described under this umbrella term. 'Dadru' is one of the twenty types of Kustha. Its correlation with cutaneous fungus infection by modern Ayurveda scholars. Itching and moist skin is the chief cardinal feature of Dadru. Various Lepa, Churna, Asawa and Vati etc., are mentioned in various Classical Text. Very few medicines are tested for their efficacy and toxicity on animals, and their clinical study is evaluated. While these medicines are very frequently used in day to day clinical practice. To improve the compliance and global acceptance of the Ayurvedic medicine standardization, toxicity study, experimental study and conversion into new dosage forms are required. Conventional Dadrughn Lepa was converted into its cream by adding Polysorbate 80, Cetomacrogol B.P., Carbopol and glycerine. This study aims to investigate the In-vitro antifungal property of the Dadrughn lepa, Dadrughn oil and Dadrughn Cream to evaluate against three common dermatophytic species, viz. Microsporum canis, Trichophyton rubrum and Epidermophyton floccosum adopting Agar cup diffusion technique. The studied drug shows very enthusiastic result to treat the fungal disease of the skin.

Keywords: Dadru, Dermatophyte, Sneha-paka, Antifungal activity, Agar cup diffusion.

Copyright @ 2020: This is an open-access article distributed under the terms of the Creative Commons Attribution license which permits unrestricted use, distribution, and reproduction in any medium for non-commercial use (NonCommercial, or CC-BY-NC) provided the original author and source are credited.

\section{INTRODUCTION}

The fungal diseases of the skin can be divided into superficial mycoses and deep mycoses. Dermatophytosis come under superficial fungal infections of the skin. While deep mycoses always involve systemic conditions. Dermatophytosis refers to infection of keratinised structures (skin, hair and nails) caused by dermatophytes (a group of keratinophilic fungi). Dermatophytosis commonly called as tinea or ringworm. The infections caused may be acute or chronic (persistent dermatophytosis that runs a chronic course with episodes of remission and exacerbation).

Dermatophytic fungi are hyaline filamentous fungi that digest keratin by enzymatic means but are unable to invade living tissue. Several pathological changes occur in the infected host because of the fungi themselves and their metabolic products, Dermatophytic fungi digest keratin by their keratinases and are resistant to cycloheximide. Dermatophytes are classified based on their habitat and their genus [1] Habitat wise they are classified into anthropophilic, zoophilic and geophilic while according to genus they are Microsporum, trichophyton and epidermophyton. Their species like M. Canis, T. Ruburum and $E$ floccosum occur commonly worldwide, and these are the most common cause of skin infection in the northern part of India. Description of some common dermatophytes is mentioned in Table-1. 
Table-1: Types of disease caused by dermatophytes and their anatomical site involved [2]

\begin{tabular}{|c|c|c|c|}
\hline S. No & Disease & Common causative agents & Anatomic site involved \\
\hline 1 & Tinea capitis & $\begin{array}{l}\text { Microsporum any species } \\
\text { Trichophyton most species }\end{array}$ & Ringworm of the scalp; favus and kerion are variants \\
\hline 2 & Favus & $\begin{array}{l}\text { T. schoenleinii } \\
\text { T. violaceum } \\
\text { M. gypseum }\end{array}$ & $\begin{array}{l}\text { The chronic type of ringworm involving hair follicles. It } \\
\text { leads to alopecia and scarring. }\end{array}$ \\
\hline 3 & Tinea barbae & $\begin{array}{l}\text { T. rubrum } \\
\text { T. mentagrophytes } \\
\text { T. verrucosum }\end{array}$ & Involves bearded areas of the neck and face \\
\hline 4 & Tinea imbricate & T. concentricum & $\begin{array}{l}\text { A special type of Tinea corporis found in the tropics, } \\
\text { which presents with characteristic extensive concentric } \\
\text { rings of papula squamous scaly patches }\end{array}$ \\
\hline 5 & Tinea corporis & $\begin{array}{l}\text { T. rubrum and any other } \\
\text { dermatophyte }\end{array}$ & Ringworm of the smooth or non-hairy skin of the body \\
\hline 6 & T cruris & $\begin{array}{l}\text { E. floccosum } \\
\text { T. rubrum }\end{array}$ & Involves the groin and perineum \\
\hline 7 & $\mathrm{~T}$ pedis & $\begin{array}{l}\text { T. rubrum } \\
\text { E. floccosum }\end{array}$ & Ringworm of the foot \\
\hline 8 & $\begin{array}{l}\text { Ectothrix hair } \\
\text { infection }\end{array}$ & $\begin{array}{l}\text { Microsporum species } \\
\text { T. rubrum } \\
\text { T. mentagrophytes }\end{array}$ & Hair infection \\
\hline 9 & $\begin{array}{l}\text { Endothrix } \\
\text { hair infection }\end{array}$ & $\begin{array}{l}\text { T. schoenleinii } \\
\text { T. tonsurans } \\
\text { T. violaceum }\end{array}$ & Hair infection \\
\hline 10 & Tinea manuum & & Involves the hand \\
\hline 11 & Tinea unguium & & involves the nails \\
\hline
\end{tabular}

The frequency of this disease has increased significantly due to many reasons $[3,4]$, and the situation has worsened with the increase in the number of immune-compromised hosts [5]. There are several synthetic antifungal drugs present in the market. However, their effect is minimised due to several factors like low potency, poor solubility, development of resistant strains, drug toxicity and side effects, like gastrointestinal disturbances, cutaneous reaction, hepatotoxicity, leucopenia etc [6-10]. The decreased availability of efficient, non-toxic antifungals and increased number of treatment failures have motivated current researchers to search for therapeutic alternatives.

In Indian sub-continent, Ayurvedic medicines have been the basis of treatment and cure of various diseases from centuries. Numerous antifungal medicines are mentioned in various textbooks of Ayurveda which are used to cure various skin infections and other diseases. Despite their slow action, their therapeutic use is becoming popular because of lower side effects. Unlike synthetic drugs, Ayurvedic medicines have the ability to control resistant microorganisms. These Ayurvedic drugs have been used from centuries to cure various cutaneous fungal infections (Kustha Roga), but there is no scientific explanation for their actions. In this research work, an initiative was taken to prove the antifungal activity of one such common Ayurvedic formulation on an experimental basis.
For this, an Ayurvedic formulation named Dadrughn Lepa [11] was taken for study to assess the antifungal effect on dermatophytes along with its two more derivative variants, i.e. Dadrughn oil and Dadrughn Cream. Based on symptomatology Dadru have simulated with 'Dermatophytosis.'

\section{MATERIAL AND METHOD Dadrughn Lepa Preparation}

This formulation is mentioned in Sharangdhar Samhita, and no reference is found regarding this formulation in any other Ayurvedic texts. Chakrmard (Cassia tora), Til (Sesamum indicum), Kusth (Sausseria Lapa), Haridra (Curcuma longa), and Siddharthak (Sinapis alba) were taken in an amount of $50 \mathrm{gms}$ grinded separately in the Mixer-grinder at $17000 \mathrm{rpm}$. and vigorously mixed with Sarshap (Brassica compestris) oil to make a homogeneous mixture having thick paste-like consistency into Lepa.

The content of Dadrughn Lepa is considered as a principal ingredient, and their two newer preparations were formulated and developed.

1. Dadrughn oil

2. Dadrughn Cream

\section{Dadrughn Oil Preparation}

It is prepared as an intermediate formulation to prepare cream from conventional Lepa. Dadrughn oil is prepared according to the fundamental preparatory method of oil preparation mentioned in Sharangdhar Samhita. All contents of Dadrughn Lepa (300gm) were 
taken in equal amount as Kalka dravya (Paste of Herbs) for Sneha-paka (Medicated oil formulation techniques), and Paka was done by adding four times of Sershpa Taila (Mustad oil) $1200 \mathrm{ml}$ and 16 times water (4800ml) till that all Sneha-siddhi 'Lakshanas'(finished product quality control features of medicated oil ) were attained.

\section{Dadrughn Cream Preparation}

The cream was prepared by adding the water phase into the oil phase. The oil phase was prepared by adding POLYSORBATE 80 [12], CETOMACROGOL B.P. [13] to Dadrughn Taila. This mixture was then heated at $600 \mathrm{C}$ on a hot plate till CETOMACROGOL B.P. gets dissolved whereas the water phase was prepared by adding Glycerin [14] to the water and mixed with the help of a spatula. This mixture was heated at $60 \mathrm{o} \mathrm{C}$ on a hot plate for 5 minutes. The water phase was incorporated into the oil phase slowly and was mixed with the help of the Pulveriser machine for $30 \mathrm{~min}$ and left for cooling. A mixture of Carbopol [15] and water was then added to make mixture thick. This homogeneous mixture was then packed in sterile tubes for further analysis in ambient condition. This formulation was pass through various optimization phases and the contents of the optimized cream and their amount are mentioned in Table-2.

Table-2: Ingredients used in the preparation of Cream

\begin{tabular}{|l|l|l|}
\hline S. No & Name of the ingredients & Quantity \\
\hline 1. & Dadrughn Taila & $100 \mathrm{ml}$ \\
\hline 2. & POLYSORBATE 80 & $12.5 \mathrm{gm}$ \\
\hline 3. & CETOMACROGOL BP & $12.5 \mathrm{gm}$ \\
\hline 4. & Glycerine & $60 \mathrm{gm}$ \\
\hline 5. & Water & $40 \mathrm{ml}$ \\
\hline 6. & Carbopol & $1 \mathrm{gm}$ \\
\hline
\end{tabular}

\section{Collection of Fungal strains}

Fungal strains were procured from Institute of Microbial Technology (IMTECH), Chandigarh (India). The organisms tested were Trichophyton rubrum (MTCC 8477), Epidermophyton floccosum (MTCC 7880), and Microsporum canis (MTCC 2820). The procured samples were sub-cultured and maintained in Sabouraud Dextrose Agar (HIMEDIA) slants at 40 oC.

\section{IN VITRO ASSAY \\ Culture Preparation}

- The freshly prepared slant of M. canis, E. floccosum \& T. rubrum was used.

- Wash the slant by using $10 \mathrm{~mL}$ of sterile Normal saline solution.

\section{METHODOLOGY: Cylinder Plate Method Media Preparation}

Sabroud Dextrose Agar was used for determining the activity of $M$. canis, E. floccosum \& Potato Dextrose Agar was used for assessing the activity of T. rubrum. Media was prepared as per the instruction provided by the Manufacturer. The media was then autoclaved at $121^{\circ} \mathrm{C}$ temperature \& $15 \mathrm{lbs}$ pressure for 20 minutes.

\section{Sample Preparation for Oil, Cream \& Lepa}

Take 1 gm, 2 gm \& 3gm of Dadrughna Lepa, oil \& cream into a different conical flask. Add $10 \mathrm{ml}$ mixture of Methanol and DMSO into a ratio of 7:3. Sonicate the samples for 10 mins to thoroughly mix drugs sample with reagents. Reflux the sample for $1 \mathrm{hr}$. At $80^{\circ} \mathrm{C}$ on a water bath. Filter the samples. The filtrate was used as a test sample for the in-vitro anti-fungal efficacy study. 5\% w/v Ketoconazole was used as a positive control for this study.

\section{TESTING PROCEDURE For Anti-Fungal Activity}

Cooldown sterile media up to $55^{\circ} \mathrm{C}$ and add $10 \mu 1$ of different fungal cultures into SDA \& PDA flasks, Mixed it slowly. Labelled the plates \& then poured $25 \mathrm{ml}$ of media by sterile measuring cylinder. The plate was solidified and made required wells at a proper distance by sterile borer on plates. Add test samples \& blank in respected labelled well. When samples were diffused completely in well, incubate SDA \& PDA plate into Biological Oxygen demand incubator at $25^{\circ} \mathrm{C}$ for 48 hours observe the zone of inhibition.

\section{RESULTS \& OBSERVATION}

Table-3: In-vitro antifungal activity of Dadrughna Lepa Dadrughna Oil Dadrughna Cream

\begin{tabular}{|l|l|l|l|l|l|}
\hline \multirow{2}{*}{ S. No } & \multicolumn{2}{|c|}{ Name of sample } & \multicolumn{2}{l|}{ Zone of Inhibition } \\
\cline { 3 - 6 } & & $\begin{array}{l}\text { Microsporum } \\
\text { Canis }\end{array}$ & $\begin{array}{l}\text { Trichophyton } \\
\text { rubrum }\end{array}$ & $\begin{array}{l}\text { Epidermophyton } \\
\text { Floccosum }\end{array}$ \\
\hline 1 & Ketoconazole & $33 \mathrm{~mm}$ & $29 \mathrm{~mm}$ & $31 \mathrm{~mm}$ \\
\hline 2 & Blank - Methanol: DMSO & $\mathrm{NZ}$ & $\mathrm{NZ}$ & $\mathrm{NZ}$ \\
\hline 3 & \multirow{2}{*}{ Dadrughna Lepa } & $1 \mathrm{gm}$ & $17 \mathrm{~mm}$ & $21 \mathrm{~mm}$ & $\mathrm{NZ}$ \\
\cline { 3 - 6 } & & $2 \mathrm{gm}$ & $18 \mathrm{~mm}$ & $22 \mathrm{~mm}$ & $\mathrm{NZ}$ \\
\cline { 3 - 6 } & $3 \mathrm{gm}$ & $19 \mathrm{~mm}$ & $24 \mathrm{~mm}$ & $16 \mathrm{~mm}$ \\
\hline 3 & \multirow{2}{*}{ Dadrughna Oil } & $1 \mathrm{gm}$ & $20 \mathrm{~mm}$ & $26 \mathrm{~mm}$ & $\mathrm{NZ}$ \\
\cline { 3 - 6 } & & $2 \mathrm{gm}$ & $21 \mathrm{~mm}$ & $27 \mathrm{~mm}$ & $\mathrm{NZ}$ \\
\cline { 3 - 6 } & & $3 \mathrm{gm}$ & $22 \mathrm{~mm}$ & $30 \mathrm{~mm}$ & $20 \mathrm{~mm}$ \\
\hline 3 & \multirow{3}{*}{ Dadrughna Cream } & $1 \mathrm{gm}$ & $18 \mathrm{~mm}$ & $23 \mathrm{~mm}$ & $\mathrm{NZ}$ \\
\cline { 3 - 6 } & & $2 \mathrm{gm}$ & $19 \mathrm{~mm}$ & $24 \mathrm{~mm}$ & $\mathrm{NZ}$ \\
\cline { 3 - 6 } & & $3 \mathrm{gm}$ & $20 \mathrm{~mm}$ & $28 \mathrm{~mm}$ & $18 \mathrm{~mm}$ \\
\hline
\end{tabular}


Table-4: Activity index of In-vitro anti-microbial study done on Dadrughna Lepa, Dadrughna Oil and Dadrughna Cream.

\begin{tabular}{|c|c|c|c|c|c|}
\hline \multirow[t]{2}{*}{ S.No } & \multicolumn{2}{|c|}{ Name of sample } & \multicolumn{3}{|l|}{ Activity index } \\
\hline & & & $\begin{array}{l}\text { Microsporum } \\
\text { canis }\end{array}$ & $\begin{array}{l}\text { Trichophyton } \\
\text { rubrum }\end{array}$ & $\begin{array}{l}\text { Epidermophyton } \\
\text { Floccosum }\end{array}$ \\
\hline \multirow[t]{3}{*}{1} & \multirow[t]{3}{*}{ Dadrughna Lepa } & $1 \mathrm{gm}$ & 0.51 & 0.72 & 0.00 \\
\hline & & $2 \mathrm{gm}$ & 0.54 & 0.75 & 0.00 \\
\hline & & $3 \mathrm{gm}$ & 0.57 & 0.82 & 0.51 \\
\hline \multirow[t]{3}{*}{2} & \multirow[t]{3}{*}{ Dadrughna Oil } & $1 \mathrm{gm}$ & 0.60 & 0.89 & 0.00 \\
\hline & & $2 \mathrm{gm}$ & 0.63 & 0.93 & 0.00 \\
\hline & & $3 \mathrm{gm}$ & 0.66 & 1.03 & 0.64 \\
\hline \multirow[t]{3}{*}{3} & \multirow[t]{3}{*}{ Dadrughna Cream } & $1 \mathrm{gm}$ & 0.54 & 0.79 & 0.00 \\
\hline & & $2 \mathrm{gm}$ & 0.57 & 0.82 & 0.00 \\
\hline & & $3 \mathrm{gm}$ & 0.60 & 0.96 & 0.58 \\
\hline
\end{tabular}

\section{DISCUSSION}

Antifungal activity of formulations

1. DMSO did not show any antifungal activity against any strain. So, it did not interfere with the result of the study.

2. Ketoconazole was highly effective against $M$. canis and least against $T$. rubrum while different dosage forms of Dadrughn Lepa shows that T. rubrum was a highly susceptible genus of fungus while $E$. floccosum was least. Zone of inhibition was of almost equal area. So, its pharmaceutical action was the same in the all chosen strain of dermatophytes.

3. Antifungal activity of Dadrughn Lepa against $M$. canis, T. rubrum was found effective even in low dose and zone of inhibition increases with the increase in the concentration of the drug. No zone of inhibition seen in E. Floccosum at a low dose but at a dose of $3 \mathrm{gm}$ its activity was equivalent to half of the standard drug.

4. Antifungal activity of Dadrughn oil against $M$. canis, T. rubrum was found effective even in low dose and zone of inhibition increases with the increase in the concentration of the drug. No zone of inhibition seen in E. Floccosum at a low dose but at a dose of $3 \mathrm{gm}$ its activity is $2 / 3$ to standard drug.

5. Antifungal activity of Dadrughn cream against $M$. canis, T. ruberum was found effective in low dose and zone of inhibition increases with the increase in the concentration of the drug. No zone of inhibition seen in E. Floccosum at a low dose but at a dose of $3 \mathrm{gm}$ its activity is $2 / 3$ to standard drug.

Effect of concentration of drug on different strains of dermatophytes:

1. It was found that antifungal activity of $M$. canis grows steadily, increases exponentially in $T$. rubrum and case of E. floccosum, does not shows any antifungal activity below $3 \mathrm{gm}$.

2. Order of Antifungal Activity in 3 strains was as follows.
a. M. canis: $\mathrm{Kz}>\mathrm{DO}>\mathrm{DC}>\mathrm{DL}$
b. T. rubrum: $\mathrm{DO}>\mathrm{Kz}>\mathrm{DC}>\mathrm{DL}$
c. E. floccosum: $\mathrm{Kz}>\mathrm{DO}>\mathrm{DC}>\mathrm{DL}$

\section{CONCLUSION}

From the observations, it can be concluded that Dadrughna Lepa, oil \& cream shows good antifungal activity on Microsporum canis, Trichophyton rubrum \& Epidermophyton floccosum. Dadrughn Lepa and its other modified dosage forms are highly effective against $T$. rubrum and show the equivalent result to ketoconazole at a concentration above $3 \mathrm{gm}$. In the case of other dermatophytes, i.e. M. canis and E. flocossum their activity is $2 / 3 \mathrm{rd}$ as compared to ketoconazole. At a dose of $3 \mathrm{gm}$ of Dadrughn Lepa and its newer modified dose result was found that acceptable susceptibility against all the three strains of dermatophytes. Thus, it will be highly effective when it is applied in thick coat. Dadrughn Lepa has high potential as an antifungal agent when it is formulated by 'Sneha-paka Kalpana' method. Mustard oil potentiated the antifungal effect and it also increases the retention time of the drug over the applied surface. This study also reveals that the conventional preparation of Dadrughn Lepa may be modified into a newer topical dosage form like cream and ointment etc. Dadrughn Lepa and its modified dosage form against the test organism could be used in the treatment of Ringworm and other cutaneous fungal infections.

\section{REFERENCES}

1. Baveja, C. P. (2015). Textbook of microbiology, 5th edition 2015, Arya publication, 548-550

2. Ananth, N., \& Paniker. (2014). Textbook of microbiology, 19th edition reprint 2014 Universities Press (India) Privet limited, 596-598

3. Weitzman, I., \& Summerbell, R. C. (1995). The dermatophytes. Clinical microbiology reviews, 8(2), 240-259.

4. Jessup, C. J., Warner, J., Isham, N., Hasan, I., \& Ghannoum, M. A. (2000). Antifungal susceptibility testing of dermatophytes: establishing a medium for inducing conidial growth and evaluation of susceptibility of clinical isolates. Journal of clinical microbiology, 38(1), 341-344.

5. Pinto, E., Pina-Vaz, C., Salgueiro, L., Gonçalves, M. J., Costa-de-Oliveira, S., Cavaleiro, C., ... \& Martinez-de-Oliveira, J. (2006). Antifungal 
activity of the essential oil of Thymus pulegioides on Candida, Aspergillus and dermatophyte species. Journal of medical microbiology, 55(10), 1367-1373.

6. Agrawal, A. N. U. R. A. G., Srivastava, S. H. A. L. I. N. I., Srivastava, J. N., \& Srivasava, M. M. (2004). Evaluation of inhibitory effect of the plan phyllanthus amarus against dermatophytic fungi microsporum gypserum. Biomedical and Environmental Sciences, 17(3), 359-365.

7. Del Aguila, R., Montero Gei, F., Robles, M., Perera- Ramirez, A., \& Male, O. (1992). Once- weekly oral doses of fluconazole $150 \mathrm{mg}$ in the treatment of tinea pedis. Clinical and experimental dermatology, 17(6), 402-406.

8. Torok, I., \& Stehlich, G. (1993). Double blind comparative examination of Ketokonazole $1 \%$ cream and Clotrimazole $2 \%$ ointment in superficial dermatomycoses. Ther Hung, 41, 6063.
9. López- Gómez, S. A. R. A., Del Palacio, A. M., Van Cutsem, J. A. N., Cuetara, M. S., Iglesias, L., \& Rodriguez- Noriega, A. N. (1994). Itraconazole versus griseofulvin in the treatment of tinea capitis: a double- blind randomized study in children. International journal of dermatology, 33(10), 743-747.

10. Rosso, D. (1998). Hepatitis associated with terbinafine therapy: three case reports and a review of the literature. Clinical and experimental dermatology, 23(2), 64-67.

11. Shailja, S., \& Sharangdhar, S. (2013). Chaukhamba Publication, Varanasi, Uttarkhand, 2013;11(56):435,

12. https://en.m.wikipedia.org/wiki/Polysorbate_80

13. https://en.m.wikipedia.org/wiki/Cetomacrogol_10 00

14. https://en.m.wikipedia.org/wiki/Glycerol

15. http://www.silverson.com/us/resourcelibrary/application-reports/ dispersion-andhydration-of-carbopol 